\title{
Two-Dimensional Mathematical Modelling of a Dam-Break Wave in a Narrow Steep Stream
}

\author{
Mario Krzyk ${ }^{1}$ - Roman Klasinc ${ }^{2}$ - Matjaž Četina ${ }^{3}$ \\ 1,3 University of Ljubljana, Faculty of Civil and Geodetic Engineering, Slovenia \\ ${ }^{2}$ Graz University of Technology, Institute of Hydraulic Eng. and Water Resources Management, Austria
}

\begin{abstract}
The paper deals with hydraulic aspects of a wave, emerging as a result of a potential dam break of the upper storage reservoir of the pumpedstorage hydropower plant Kolarjev vrh. A two-dimensional depth-averaged mathematical approach was used. The upper storage reservoir and its dam failure were modelled with the mathematical model PCFLOW2D, which is based on the Cartesian coordinate numerical mesh. The results of PCFLOW2D were used as the upper boundary condition for the mathematical model PCFLOW2D-ORTHOCURVE, based on the orthogonal curvilinear numerical mesh. The model PCFLOW2D-ORTHOCURVE provided a tool for the analysis of flood wave flow in a steep, narrow and geometrically diversified stream channel. The classic Manning's equation fails to give good results for streams with steep bed slopes and therefore, a different equation should be used. The application of the Rickenmann's equation was chosen, presented in a form similar to Manning's equation. For the purpose of the example given here, the equation was somewhat simplified and adapted to the data available. The roughness coefficient used at each calculation cell depended on the slope of that cell. The results of numerical calculations were compared to measurements carried out on a physical model in the scale of $1: 200$. Regarding the complexity of the flow phenomenon a rather good correlation of maximum depth was established: only at one gauge the difference in water depth was up to $27 \%$ while at the other four it was $7 \%$ of water depth on average.
\end{abstract}

Keywords: dam-break wave, steep curved channels, two-dimensional mathematical model, orthogonal curvilinear coordinates, roughness coefficient, model PCFLOW2D-ORTHOCURVE

\section{O INTRODUCTION}

Mathematical modelling has taken a leading role in solving certain practical problems and is used more frequently than physical models. Nevertheless, physical modelling remains irreplaceable for solving many problems. One of these is establishing hydrodynamic flow characteristics with complex geometry features, where capturing all geometrical details is too difficult for mathematical modelling. Moreover, many problems can only be solved with a simultaneous use of both, physical and mathematical models. Such is also the case of a potential dam failure at the Kolar's peak (Kolarjev vrh, NE Slovenia), where measurement results of unsteady flow on the physical model provided the basis for verifying the mathematical model PCFLOW2D-ORTHOCURVE. As the upper storage reservoir of pumped hydro power plant (HPP) Kolarjev vrh is planned as artificial accumulation built by dykes, the reason of dyke damaging could also be uncontrolled water hammer [1] and [2].

The planned installed power of the pumpedstorage HPP Kolarjev vrh is $300 \mathrm{MW}$, with the height difference of up to $714.7 \mathrm{~m}$, depending on the water levels in both storage reservoirs. The installed turbine flow would be $51 \mathrm{~m}^{3} / \mathrm{s}$ and the pumps would have a discharge of $37 \mathrm{~m}^{3} / \mathrm{s}$. The upper storage reservoir would be connected to the powerhouse with a pressure penstock $2660 \mathrm{~m}$ long and 3.0 to $3.5 \mathrm{~m}$ in diameter. As the lower storage reservoir of the pumped-storage HPP Kolarjev vrh, the existing storage reservoir of HPP Fala on the Drava River would be used. At the Water Management Institute in Ljubljana, a physical model of the upper storage reservoir was made, together with the valley lying to the south in the scale of $1: 200$ [3]. The view of the storage reservoir and modelled valley (upper narrow part) with measurement gauges is shown in Fig.1.

The upper storage reservoir would be located on the flattened Kolarjev vrh. The level of the reservoir bottom would be at $975.0 \mathrm{~m}$ a. s. 1., with maximum dimensions of $350 \times 750 \mathrm{~m}$. The storage reservoir would comprise an area of $160,000 \mathrm{~m}^{2}$. The bank slope on the inner side of the storage reservoir would be approximately $1: 2$, and on the outer side $1: 1.5$. The crest elevation would be $996.5 \mathrm{~m}$ a. s. $1 ., 1.5 \mathrm{~m}$ above the highest water level in the upper reservoir ( $995.0 \mathrm{~m}$ a. s. 1.) and would have a width of $5 \mathrm{~m}$. The water volume in the reservoir would be approximately $2.8 \times 10^{6} \mathrm{~m}^{3}$. An axonometric view of the upper storage reservoir that was built in the physical model is presented in Fig. 2, together with the position of gauges that recorded water level oscillations. The measurement results at these gauges were used for the verification of the mathematical model PCFLOW2D, which was used for hydrodynamic modelling of flow in the upper reservoir. 


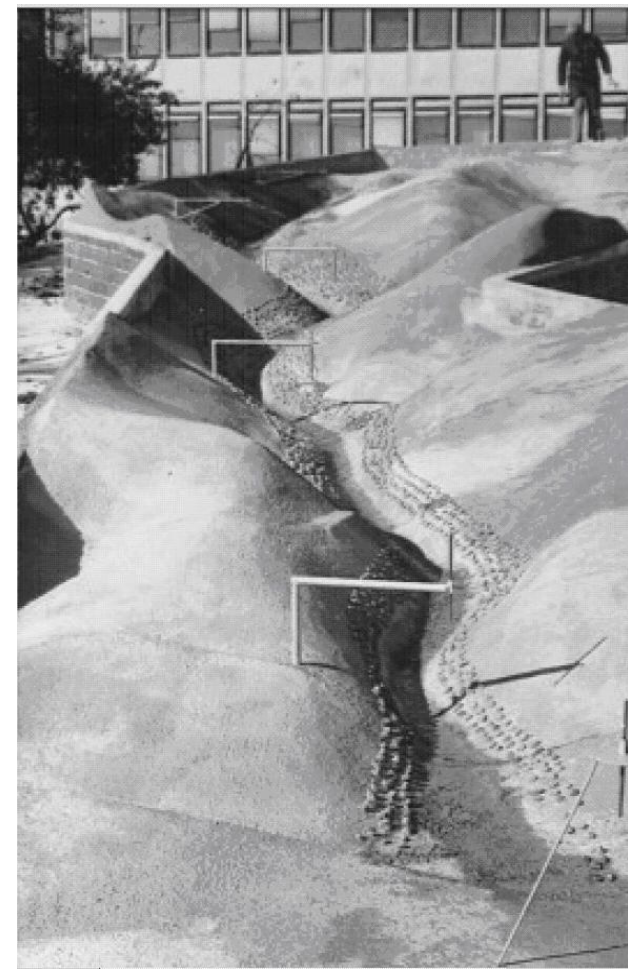

Fig. 1. Photo of physical model of south valley with installed gauges

A topographic analysis of terrain below the upper storage reservoir of HPP Kolarjev vrh has shown that during a dam break of the upper storage reservoir, the potential discharge spillways are the three valleys gravitating to the Drava River. Since the physical model was made only to facilitate the verification of results of the mathematical model, only the shortest, south valley of the Logar's Creek (Logarjev potok) was built. The part of the dam gravitating to the valley is approximately $1 \mathrm{~km}$ long. The length of the waterway spilling from the reservoir to the town of
Selnica lying approximately $700 \mathrm{~m}$ below is $6 \mathrm{~km}$, of which $4500 \mathrm{~m}$ are represented by a fairly narrow valley that passes into the wide valley of the Drava River. To verify the results of the mathematical model PCFLOW2D-ORTHOCURVE, data relating to the narrow part of the valley were used.

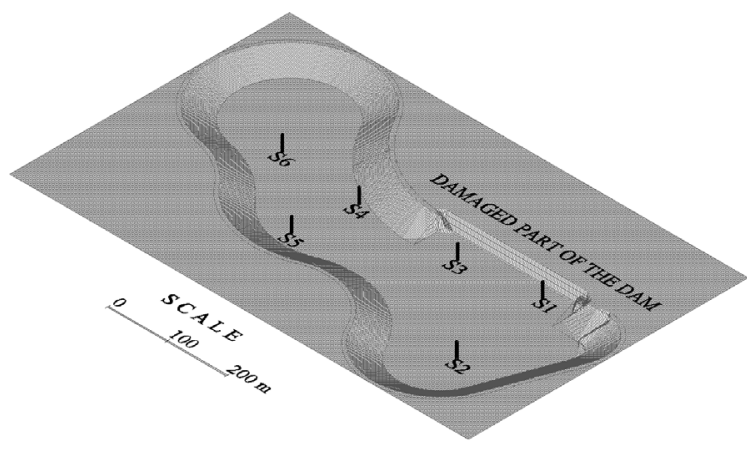

Fig. 2. Axonometric view of the upper storage reservoir with positions of measuring gauges

In the physical model, the analysis of the dambreak wave caused by an instantaneous break of part of the dam was performed. Several possible widths of a dam breach were considered, namely 48, 99, 237 and $433 \mathrm{~m}$. The length of the flow under study was $4620 \mathrm{~m}$, and the head difference between the reservoir bottom ( $975 \mathrm{~m}$ a. s. 1.) and the more flat part of the valley was $646 \mathrm{~m}$. The average channel slope was $14 \%$. In order to monitor the motion of the wave and its characteristics on the physical model, six gauges were set up in the upper part of the valley and six in the lower part of the valley. For the purpose of this study, only the results of the first five gauges are of interest, because other gauges were positioned outside the area covered by the mathematical model. The measurements gave the propagation time of the wave front to each gauge and water depth oscillation

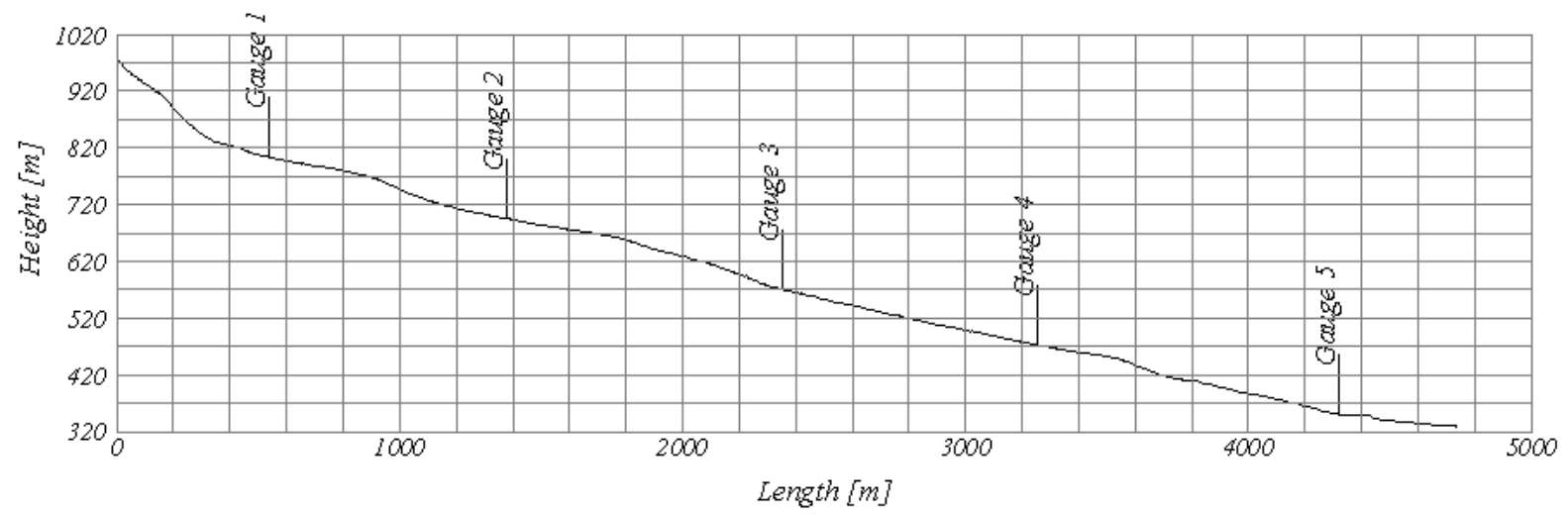

Fig. 3. Longitudinal profile of the narrow part of the south valley with the position of gauges 
at each gauge. The position of the first five gauges is shown in the longitudinal profile of the narrow part of the valley in Fig. 3. The data on water levels indicate a longitudinally non-uniform course of the wave and significant changeability of the flow between supercritical, critical and subcritical flow. The wave reached the lower part of the valley extremely fast, in three to four minutes.

\section{MATHEMATICAL MODEL OF UPPER STORAGE RESERVOIR}

For the analysis of a possible dam break wave arising from the upper storage reservoir of the HPP Kolarjev vrh, two mathematical models were prepared. The first covered the area of the reservoir and the other covered the dam break flow through the south valley to its widening. Hence, with the model of the storage reservoir and its dam-break, we acquired data on the dependence of discharge versus time at the dam site, which was used as the upper boundary condition for the second mathematical model of the downstream valley. Because of the shape of the reservoir, with no considerable difference between its width and length, the mathematical model PCFLOW2D was used for flow modelling. PCFLOW2D is based on the orthogonal Cartesian numerical mesh. For modelling the flow through the valley of the Logarjev potok, with a vast disproportion between the flow length and width with several considerable bends, the mathematical model PCFLOW2D-ORTHOCURVE was used, based on the orthogonal curvilinear numerical mesh.

As mentioned above, four different widths of a dam breach were considered in the physical model. Earlier, authors analysed the flow downstream in three consecutive bends with simplified geometry during dam breach of a width of $237 \mathrm{~m}$ with a twodimensional (2D) mathematical model [4]. The same width was chosen for the computations of the dam break wave with the models PCFLOW2D and PCFLOW2D-ORTHOCURVE.

\subsection{Basic Equations}

The mathematical model PCFLOW2D uses the orthogonal Cartesian coordinate system. The continuity (Eq. (1)) and momentum equations (Eqs. (2) and (3)) describing a two-dimensional unsteady depth-averaged flow, are written in the conservative form. The last two terms on the right hand side of Eqs. (4) and (5) express the influence of turbulent viscosity, which is determined by the $k-\varepsilon$ turbulence model. In some cases, constant values of $v_{e f}$ can also be used.

$$
\begin{gathered}
\frac{\partial h}{\partial t}+\frac{\partial(h u)}{\partial x}+\frac{\partial(h v)}{\partial y}=0 \\
\frac{\partial(h u)}{\partial t}+\frac{\partial\left(h u^{2}\right)}{\partial x}+\frac{\partial(h u v)}{\partial y}=-g h \frac{\partial h}{\partial x}-g h \frac{\partial z_{b}}{\partial x}-g h n^{2} \frac{u \sqrt{u^{2}+v^{2}}}{h^{4 / 3}}+\frac{\partial}{\partial x}\left(h v_{e f} \frac{\partial u}{\partial x}\right)+\frac{\partial}{\partial y}\left(h v_{e f} \frac{\partial u}{\partial y}\right) \\
\frac{\partial(h v)}{\partial t}+\frac{\partial(h u v)}{\partial x}+\frac{\partial\left(h v^{2}\right)}{\partial y}=-g h \frac{\partial h}{\partial y}-g h \frac{\partial z_{b}}{\partial y}-g h n^{2} \frac{v \sqrt{u^{2}+v^{2}}}{h^{4 / 3}}+\frac{\partial}{\partial x}\left(h v_{e f} \frac{\partial v}{\partial x}\right)+\frac{\partial}{\partial y}\left(h v_{e f} \frac{\partial v}{\partial y}\right) \\
\frac{\partial(h k)}{\partial t}+\frac{\partial(h u k)}{\partial x}+\frac{\partial(h v k)}{\partial y}=\frac{\partial}{\partial x}\left(h \frac{v_{e f}}{\sigma_{k}} \frac{\partial k}{\partial x}\right)+\frac{\partial}{\partial y}\left(h \frac{v_{e f}}{\sigma_{k}} \frac{\partial k}{\partial y}\right)+h G-c_{D} h \varepsilon+h P_{k v} \\
\frac{\partial(h \varepsilon)}{\partial t}+\frac{\partial(h u \varepsilon)}{\partial x}+\frac{\partial(h v \varepsilon)}{\partial y}=\frac{\partial}{\partial x}\left(h \frac{v_{e f}}{\sigma_{\varepsilon}} \frac{\partial \varepsilon}{\partial x}\right)+\frac{\partial}{\partial y}\left(h \frac{v_{e f}}{\sigma_{\varepsilon}} \frac{\partial \varepsilon}{\partial y}\right)+c_{1} \frac{\varepsilon}{k} h G-c_{2} \frac{\varepsilon^{2}}{k} h+h P_{\varepsilon v}
\end{gathered}
$$

where $t$ is time, $h$ is water depth, $u$ and $v$ are velocity components in the $x$ and $y$ directions, $z_{b}$ is the bottom level, $n$ is the Manning's friction coefficient, $g$ is acceleration due to gravity, $v_{e f}$ is the effective coefficient of viscosity, $k$ is the turbulent kinetic energy per unit of mass, $\varepsilon$ is the dissipation rate of the turbulent kinetic energy per unit of mass, $c_{1}, c_{2}, \sigma_{k}$ and $\sigma_{e}$ are constants of the turbulent model, and $P_{k v}$ and $P_{\varepsilon v}$ are production and dissipative terms due to bottom roughness.

\subsection{Boundary and Initial Conditions with Computational Details}

Boundary conditions used in the mathematical model were as follows: flow velocities through reservoir dykes were zero and at the site of the dam-break, critical flow was assumed at each cell. The sum of discharges through drainage cells represented the total outflow in the profile of the destroyed part of the 
dyke. As the initial condition in the reservoir, water level at $Z=995 \mathrm{~m}$ a.s.l. was assumed.

The size of the numerical mesh was $\Delta x=\Delta y=$ $4 \mathrm{~m}$ and the time step was $\Delta t=0.5 \mathrm{~s}$. On the basis of measurements conducted on the physical model of the downstream valley, it was estimated that it would be appropriate to monitor the time of wave propagation across the valley up to about $400 \mathrm{~s}$ after the demolition of the dyke. Therefore, maximum computation time of $420 \mathrm{~s}$ was chosen.

\subsection{Calibration and Results of the Mathematical Model of the Flow in the Reservoir}

During the calibration process of the mathematical model of the flow in the upper reservoir, we tried to find the appropriate bottom friction coefficient. For each measuring gauge presented in Fig. 2, the nearest calculation point was found and its water surface oscillation was noted. It was then compared to measured water levels on gauges of the physical model. The period of the first $160 \mathrm{~s}$ after the dyke was broken was analysed. This was also the duration of measurements recorded at gauges on the physical model.

On the basis of comparison of the computed and measured water depth oscillations on all six gauges in the area of the upper reservoir, we determined the uniform Manning's coefficient of the bottom and slopes of the dyke to be $n=0.024 \mathrm{~s} / \mathrm{m}^{1 / 3}$. As an example, the results of comparison for the gauge $\mathrm{S} 1$ are presented in Fig. 4. In Fig. 5, the resulting outflow from the reservoir is shown. This $Q-t$ curve was then used as the upper boundary condition for the mathematical model of the wave propagation in the downstream valley, which is discussed in Chapter 3 .

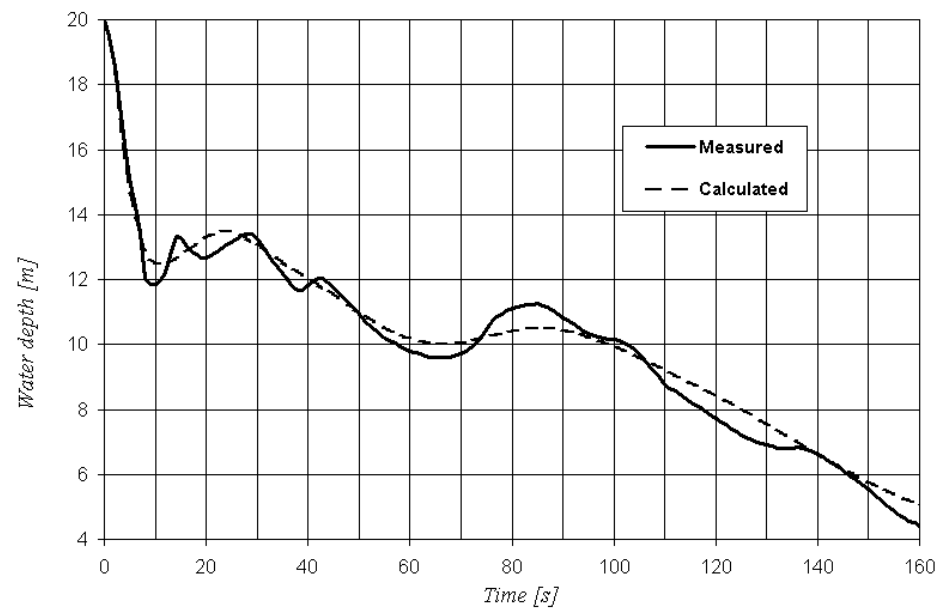

Fig. 4. Measured and calculated oscillation of water depth in the upper reservoir at gauge 1 (S1)

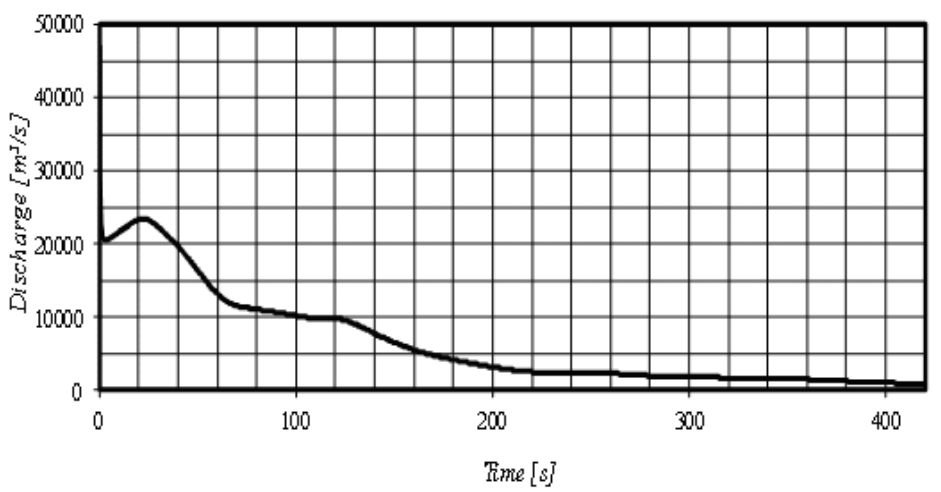

Fig. 5. The computed Q-t curve at the outflow from the reservoir 
2 MATHEMATICAL MODEL OF THE DOWNSTREAM VALLEY

\subsection{Basic Equations}

The model PCFLOW2D-ORTHOCURVE uses an orthogonal curvilinear coordinate system. The continuity Eq. (6) and momentum equations (Eqs. (7) and (8)) describing a two-dimensional unsteady depthaveraged flow are written in the conservative form.

$$
\begin{aligned}
& \frac{\partial h}{\partial t}+\frac{\partial\left(h u_{\xi}\right)}{m_{\xi} \partial \xi}+\frac{\partial\left(h v_{\eta}\right)}{m_{\eta} \partial \eta}+\frac{h u_{\xi}}{m_{\xi} m_{\eta}} \frac{\partial m_{\eta}}{\partial \xi}+\frac{h v_{\eta}}{m_{\xi} m_{\eta}} \frac{\partial m_{\xi}}{\partial \eta}=0, \\
& \frac{\partial h u_{\xi}}{\partial t}+\frac{\partial\left(h u_{\xi}^{2}\right)}{m_{\xi} \partial \xi}+\frac{\partial\left(h u_{\xi} v_{\eta}\right)}{m_{\eta} \partial \eta}+2 \frac{h u_{\xi} v_{\eta}}{m_{\xi} m_{\eta}} \frac{\partial m_{\xi}}{\partial \eta}+\left(u_{\xi}^{2}-v_{\eta}^{2}\right) \frac{h}{m_{\eta}} \frac{\partial m_{\eta}}{m_{\xi} \partial \xi}= \\
& =-g h \frac{\partial h}{m_{\xi} \partial \xi}-g h \frac{\partial z_{b}}{m_{\xi} \partial \xi}-g h n^{2} \frac{u_{\xi} \sqrt{u_{\xi}^{2}+v_{\eta}^{2}}}{h^{4 / 3}}+\frac{1}{m_{\xi} m_{\eta}}\left[\frac{\partial}{\partial \xi}\left(h v_{e f} \frac{m_{\eta}}{m_{\xi}} \frac{\partial u_{\xi}}{\partial \xi}\right)+\frac{\partial}{\partial \eta}\left(h v_{e f} \frac{m_{\xi}}{m_{\eta}} \frac{\partial u_{\xi}}{\partial \eta}\right)\right] \text {, } \\
& \frac{\partial h v_{\eta}}{\partial t}+\frac{\partial\left(h u_{\xi} v_{\eta}\right)}{m_{\xi} \partial \xi}+\frac{\partial\left(h v_{\eta}^{2}\right)}{m_{\eta} \partial \eta}+2 \frac{h u_{\xi} v_{\eta}}{m_{\xi} m_{\eta}} \frac{\partial m_{\eta}}{\partial \xi}+\left(v_{\eta}{ }^{2}-u_{\xi}{ }^{2}\right) \frac{h}{m_{\xi}} \frac{\partial m_{\xi}}{m_{\eta} \partial \eta}= \\
& =-g h \frac{\partial h}{m_{\eta} \partial \eta}-g h \frac{\partial z_{b}}{m_{\eta} \partial \eta}-g h n^{2} \frac{v_{\eta} \sqrt{u_{\xi}^{2}+v_{\eta}^{2}}}{h^{4 / 3}}+\frac{1}{m_{\xi} m_{\eta}}\left[\frac{\partial}{\partial \xi}\left(h v_{e f} \frac{m_{\eta}}{m_{\xi}} \frac{\partial v_{\eta}}{\partial \xi}\right)+\frac{\partial}{\partial \eta}\left(h v_{e f} \frac{m_{\xi}}{m_{\eta}} \frac{\partial v_{\eta}}{\partial \eta}\right)\right] \text {, }
\end{aligned}
$$

where $t$ is time, $h$ is water depth, $u_{\xi}$ and $v_{\eta}$ are the velocity components along $(\xi)$ and normal $(\eta)$ to the flow direction, $m_{\xi}$ and $m_{\eta}$ are Lamé's coefficients, $z_{b}$ is the bottom level, $n$ is the Manning's friction coefficient, $g$ is acceleration due to gravity and $v_{e f}$ is the effective coefficient of viscosity.

Since the investigated case was one involving a highly unsteady flow with rapid velocity and depth changes, we estimated that an adequate distribution of $v_{e f}$ had no significant influence on the results. Thus, a constant value of $v_{e f}=0.01 \mathrm{~m}^{2} / \mathrm{s}$ was used, based on our previous experience with unsteady flow.

\subsection{Numerical Method}

Both sets of coupled partial differential equations (1) to (5) and (6) to (8) are solved by the finite volume numerical scheme proposed by [5]. The main characteristics of the method are staggered control volumes, the so-called "hybrid" scheme and an iterative procedure of depth corrections (SIMPLE). A fully implicit scheme is used for time integration providing stable and accurate solutions even at relatively high Courant numbers (up to about 10). It is possible to simulate both subcritical and supercritical flows ([5] and [6]).
The "hybrid" scheme is a combination of the upwind and central difference scheme (application of the scheme depends of the value of the cell Peclet's number). The first order upwind scheme assures simplicity and robustness [5] and it remains stable even with very complex geometry, relatively coarse numerical grid and complicated boundary conditions. However, it can sometimes involve a certain amount of the so-called »numerical diffusion«. The problem is more serious in the case of solving transport equations of scalar quantities but can sometimes render questionable hydrodynamic results as well (e.g. when simulating a high velocity river flow with lateral inflow and recirculation zones). The way to avoid the problem of numerical diffusion is to use higher order numerical schemes [7] or/and denser numerical grids. The latter is suggested in this article and can be achieved by introducing curvilinear coordinate systems which are able to fit the irregular boundaries of the computational domain. Orthogonal or nonorthogonal curvilinear meshes can be applied. Details about the equations in curvilinear coordinate systems and description of the discretisation method can be found in [4] and [8]. 


\subsection{Computer Codes}

The source computer codes PCFLOW2D for Cartesian and PCFLOW2D-ORTHOCURVE for orthogonal curvilinear numerical meshes are written in Fortran77 and run on personal computers, workstations or large mainframe systems. For the preparation of input topographic data (pre-processing) and graphical presentation of the final results of the model (postprocessing) the AutoCAD and Quick Surf graphic packages are used [8].

In mathematical models, the following boundary conditions can be taken into account at arbitrarily chosen cells of the computational domain: a) Solid boundaries (with zero normal velocities); b) Inflows of rivers (time-dependent discharges or velocities can be prescribed); c) Time-dependent water depths or surface elevations; d) Critical flow; e) An equation of a weir; f) Wind stress can be prescribed at the water surface by giving the wind speed and the wind friction coefficient.

\section{SIMULATIONS OF FLOW IN THE DOWNSTREAM VALLEY}

\subsection{Numerical Mesh, Initial and Boundary Conditions}

Terrain of downstream south valley was defined with orthogonal curvilinear numerical mesh with 9625 cells. The resolution of the grid was variable from $4 \times 11 \mathrm{~m}$ up to $33 \times 33 \mathrm{~m}$.

In the initial stage of calculation, the downstream valley is dry. Some suggestions how to treat the problem of wetting and drying in numerical solutions are given in [9]. To meet this condition in our proposed mathematical model, low water depth was given at the beginning of calculations. We chose a minimum level of $5 \mathrm{~cm}$ and all cells with water depth lower than 5 $\mathrm{cm}$ were considered dry with flow velocity equal to 0 . During the first ten iterations inside each time step, all the cells of the computational domain were included into the computation process. If the water depth did not exceed $5 \mathrm{~cm}$, the appropriate cell was assumed to be inactive with zero velocities and initial water depth. Lower initial depths resulted in instabilities in the calculation, probably due to the high terrain gradient. Based on the actual conditions, where the wave would propagate with a depth of 15 to $20 \mathrm{~m}$, the chosen initial depth of $5 \mathrm{~cm}$ was considered negligible and thus acceptable. The minimum depth was also lower than the expected accuracy of calculations.

The inflow and outflow boundary conditions had to be defined separately. The inflow curve $Q-t$ (Fig. 5) was adopted in the model, which was the result of previous calculations of the flow in the reservoir during partial dam break. In the initial time, the discharge was $46,947 \mathrm{~m}^{3} / \mathrm{s}$, which was determined theoretically using momentum equation for the example of instantaneous dam break in the conditions of maximum water level in the reservoir. In the lower (outflow) boundary of the model, the critical depth was defined as a boundary condition. Due to the high channel slope, however, this boundary condition did not have any impact on the upstream flow.

\subsection{Determination of Friction Coefficients}

The friction coefficient of the downstream valley was determined by considering the basic laws governing flow in steep channels. One of the basic observations was that the value of Manning's coefficient was not a constant and that it depended on several parameters. These were the hydraulic radius, area of flow crosssection, flow depth, width of free water surface, characteristic grain of a channel bed, channel slope and discharge. In determining the friction coefficient, all the mentioned parameters were not used, since they were mostly not known. By using the Rickenmann's equation ([10] and [11]) and several simplifications, the dependence between the Manning's friction coefficient $(n)$ and bed slope $(I)$ was acquired:

$$
1 / n=C / I^{\alpha}
$$

Based on the chosen mean value of the friction coefficient for the discussed area of the watercourse and value of exponent $\alpha$, the values of the friction coefficient $(n)$ were distributed to all cells of the computation domain.

\subsection{Analysis of Results Calculated with the Variable Friction Coefficient}

A comparison between the measured water depth versus time curves at different gauges and the calculated depths was made during the calibration of the mathematical model, where the value of exponent $\alpha$ was 0.2 (slightly above the value of Rickenmann) for different values of the mean friction coefficient $\bar{n}$ $\left(0.04,0.045\right.$ and $\left.0.05 \mathrm{~s} / \mathrm{m}^{1 / 3}\right)$. The comparison for the last, downstream gauge 5 is shown in Fig. 6 . For the average value of the Manning's friction coefficient $\bar{n}$ $=0.05 \mathrm{~s} / \mathrm{m}^{1 / 3}$, a very good correlation of maximum depth was established, as well as the propagation time of the wave to the measuring site, even if the path of the calculated wave did not coincide perfectly with the measured one. As it can be seen from Fig. 6, the 


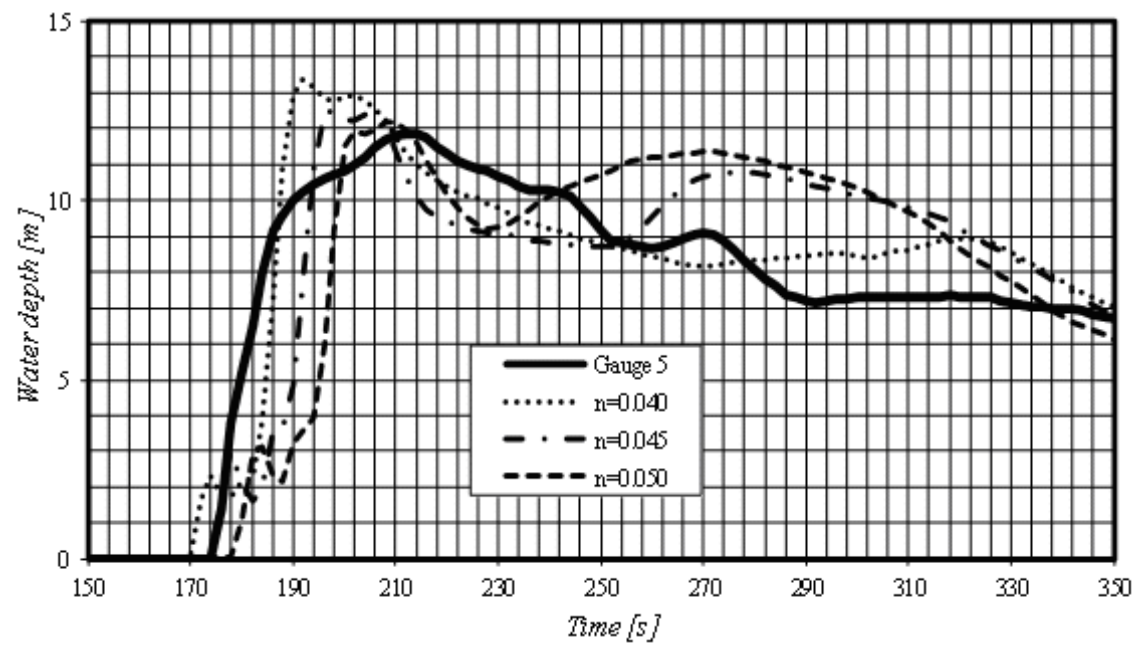

Fig. 6. Measured and calculated water depth oscillations at gauge 5 with variable friction coefficients for $\alpha=0.2$ and different average values of the Manning's friction coefficient

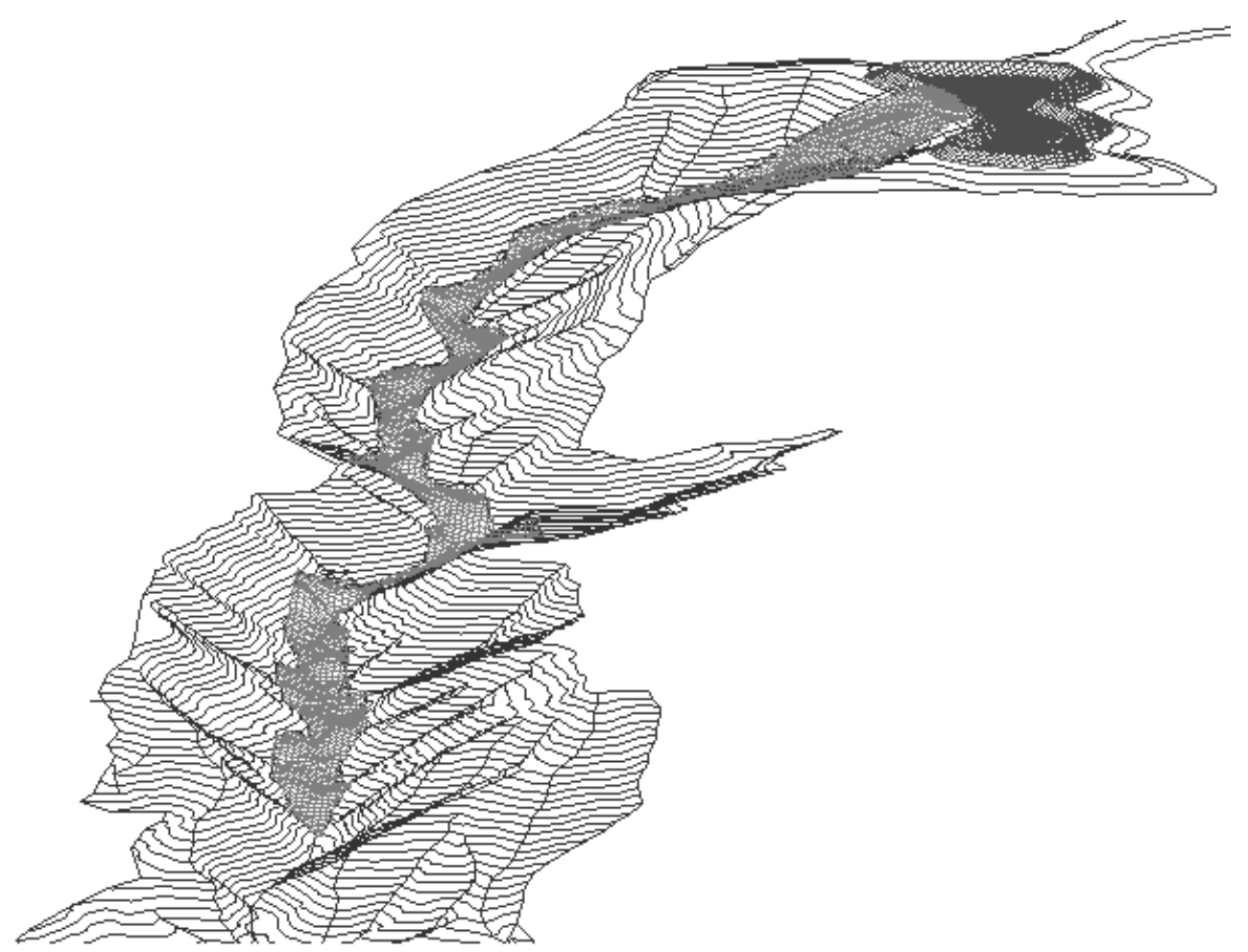

Fig. 7. Axonometric view of the wave $178 \mathrm{~s}$ after the dam break (approach of the wave front to gauge 5)

measured arrival time of the wave front to the gauge 5 is $174 \mathrm{~s}$ and the computed one $178 \mathrm{~s}(2 \%$ relative error). The same level of accuracy is achived in other gauges. Fig. 7 provides an axonometric view of the water surface along the channel at the moment of the wave approach to gauge 5 .

\section{CONCLUSIONS}

In the study of the propagation of the dam-break wave in the Logarjev potok stream and by using the Rickenmann approach to determine the friction coefficient in several gauges, we acquired very good results in relation to water level, which for different mean values of friction coefficient $\bar{n}$ 
and exponent $\alpha$ coincided well with the measured depths. The calculated wave front is somewhat too steep, which resulted from an inadequate simulation of actual occurrences in the model. Even though an instantaneous dam break was planned, this could not be carried out due to manual raising of the gate. That is why initial flows in the physical model were somewhat lower than the result of modelling of an instantaneous dam break. Very good results were obtained in relation to the wave propagation velocity. A rather good correlation of maximum depth was established - at one gauge the difference in water depth was up to $27 \%$ and at the other four it was $7 \%$ of water depth on average. In all cases, unexpectedly low friction coefficients were used. The reason lies in the large depth of the flood wave in comparison to the roughness of the river bottom. Hence, the studied case cannot be considered as a classic case of torrential flow with a relatively small depth and a much higher friction coefficient.

\section{REFERENCES}

[1] Riasi, A., Raisee, M., Nourbakhsh, A. (2010). Simulation of transient flow in hydroelectric power plants using unsteady friction. Strojniški vestnik Journal of Mechanical Engineering, vol. 56, no. 6, p. 377-384.

[2] Karadžić, U., Bergant, A., Vukoslavčević. P. (2009). A novel pelton turbine model for water hammer analysis, Strojniški vestnik - Journal of Mechanical Engineering vol. 55 , no. 6 , p. 369-380.

[3] Legiša, D., Rajar, R. (1980). Hydraulic model of the wave due to possible dam-break of the Kolarjev vrh reservoir (HPP Kozjak), Report, Water management institute and Faculty of Civil and Geodetic Engineering, Ljubljana. (in Slovene)

[4] Rajar, R., Četina, M. (1983). Two-Dimensional DamBreak Flow in Steep Curved Channels. Proceedings of the 20th IAHR Congress, Vol. II, p. 571-579.

[5] Patankar, S.V. (1980). Numerical Heat Transfer and Fluid Flow. McGraw-Hill Book Company, New York.

[6] Četina, M., Krzyk, M. (2003). Two-Dimensional Modelling of Debris-Flow Movement in Log pod Mangartom as an Example of a Non-Newtonian Fluid, Strojniški vestnik - Journal of Mechanical Engineering vol. 49, no. 3, p. 161-172.

[7] Ferrari, A., Fraccarollo, L., Dumbser, M., Toro E.F., Armanini, A. (2010). Three-Dimensional Flow Evolution after a Dambreak. Journal of Fluid Mechanics, vol. 663, p. 456-477, DOI:10.1017/ S0022112010003599.

[8] Krzyk, M. (2004). Two-dimensional mathematical modelling of flow in steep streams, Ph.D. Thesis, Univesity of Ljubljana, Faculty of Civil and Geodetic Engineering. (in Slovene)

[9] Gallardo, M., Parés, C., Castro, M. (2007). On a wellbalanced high-order finite volume scheme for shallow water equations with topography and dry areas. Journal of Computational Physics, vol. 227, no. 1, p. 574-601, DOI:10.1016/j.jcp.2007.08.007.

[10]Rickenmann, D. (1996). Fliessgeschwindigkeit in Wildbächen und Gebrigsflüssen. Wasser, energie, luft - eau, énergie, air, Baden, 88. Jhg., H. $11 / 12$, p. 298-304.

[11]Rickenmann, D. (2000). Dynamics of sediments and water in alpine catchments - processes and prediction. Scientific report WSL, Birmensdorf. 